\title{
Improving of Water Resistance of Asphalt Concrete Wearing Course Using Latex-Bitumen Binder
}

\author{
Henri Siswanto ${ }^{1,2, *}$ \\ ${ }^{1}$ The Department of Civil Engineering, The Faculty of Engineering, Universitas Negeri Malang, Jl. \\ Semarang 5 Malang, Indonesia \\ ${ }^{2}$ Konsorsium Riset Geopolimer Indonesia (KORIGI), Lab Beton dan Bahan Bangunan ITS, Surabaya, \\ Indonesia
}

\begin{abstract}
It is well known that presence of water in a bituminous mix is a critical factor which can lead to premature failure of flexible pavements. This requires solutions one of which is to formulate an asphalt mix that has a high resistance to moisture and one way to do this is to mix latex with the asphalt mix. The purpose of this experimental study was to investigate the effect of water on Marshall stability of asphalt concrete wearing course (ACWC) made with a latex-bitumen binder. Latex-bitumen was mixed with aggregate and four levels of latex content were investigated in this study, namely, $0 \%, 2 \%, 4 \%$ and $6 \%$ respectively by weight of asphalt. Wet procces was used in the blending of mixtures. The procedure used to obtain the optimum binder contents conformed to the Marshall procedure (SNI 06-2489-1991). Six Marshall specimens at optimum binder content were prepared for each binder mix investigated. Three of six specimens from each group were tested under Marshall standards. The remaining specimens were tested by immersion in a bath at $60^{\circ} \mathrm{C}$ for 24 hours. The Marshall index of retained stability was used to evaluate the effect of water on the Marshall stability of ACWC. The results indicated that the addition of up to $4 \%$ latex to ACWC mix increased the retained Marshall stability, whereas the addition of latex above $4 \%$ decreased the retained stability of the mixture. The addition of $4 \%$ CRM significantly improved the retained stability of the mixture and was the best latex - ACWC mix.
\end{abstract}

\section{Introduction}

Many variables affect the degree of moisture damage which occurs in an asphalt concrete mixture and some of these variables are related to the materials forming hot mix asphalt (HMA) such as aggregate and bitumen. Others are related to mixture design and construction (air void levels, film thickness, permeability and drainage), environmental factors (temperature, pavement age, freeze-thaw cycles, and presence of ions in the water), traffic conditions and type and properties of the additives [1].

\footnotetext{
* Corresponding author: henri.siswanto.ft@um.ac.id
} 
As in many tropical countries, the main causes of road deterioration in Indonesia are from high road surface temperatures, high rainfalls and high traffic loads [2]. Indonesia experiences frequent floods and these floods are a major cause of pavement damage by stripping/ separating the bitumen layers from the aggregate thus contributing to its deterioration.

Traffic and water are two key elements in the degradation of asphalt concrete pavements, water causes loss of adhesion at the bitumen-aggregate interface. This premature failure of adhesion is commonly referred to as stripping in asphalt concrete pavements. Strength is impaired since the mixture ceases to act as a coherent structural unit and loss of adhesion renders the cohesive resistance of the interstitial bitumen body useless. Water may enter the interface through diffusion across bitumen films and penetrate directly into partially coated aggregate. Futhermore, water can cause stripping through five different mechanisms, namely, detachment, displacement, spontaneous emulsification, pore pressure and hydraulic scour [3]. The solution of this problem is to obtain an asphalt mixture that has a high resistance to water.

Additives have been used to improve endurency of asphalt concrete pavements to permanent deformation, moisture damage, and fatigue or low-temperature cracks. There are a number of different additives available which can be introduced directly to the asphalt cement as a binder modifier, or can be added to the mixture with the aggregate [4].

One of the more promising additives is latex which improves its resistance to water. Research has shown that the addition of latex not only reduces asphalt's sensitivity to heat but also improves its binding and thus durability[5]. Latex improves the physical properties of asphalt by incresing its softening point and durability [6].

Asphalt concrete wearing course (ACWC) is widely used as road pavement in Indonesia and latex as an additive has the potential of increasing ACWC water resistance and thus its durability, therefore, the purpose of this experimental study was to investigate the effect of water on Marshall stability of asphalt concrete wearing course (ACWC) made with a latex-bitumen binder. The approach of this study was to find ways to improve the retained stability of ACWC. The higher the level of retained stability, the higher the water resistance of the mix.

\section{Method}

\subsection{Materials}

The materials used in this study were a 60/70 penetration bitumen, aggregate and latex. The latex used in this research was natural rubber of $60 \%$ dry rubber content (DRC 60) available in Indonesia. The aggregate gradation used can be seen in Figure 1. The Indonesian National Standards (SNI 1737-1989) were used and all test results had to meet SNI standards. 


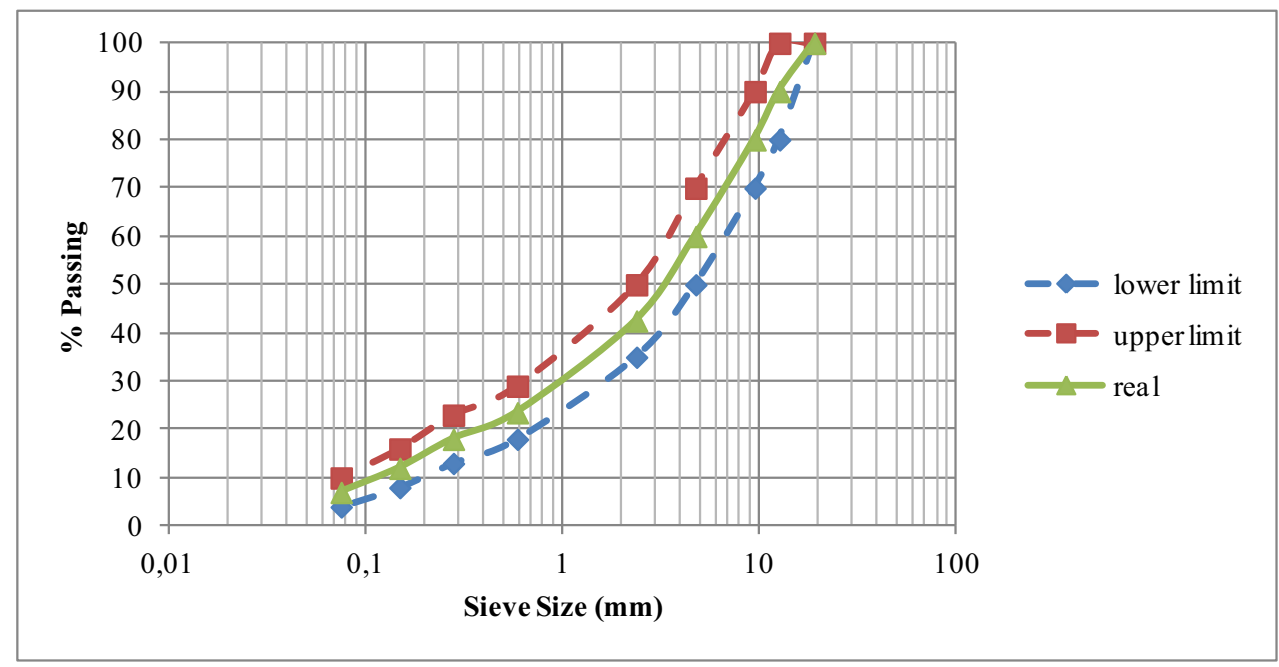

Fig. 1. The Grading Curves of Asphalt Concrete Wearing Course.

\subsection{Blending latex and bitumen method}

According to Road Note 36 Specification for the Manufacture and Use of Rubberised Bituminous road materials and binders, the method of blending rubber with penetration grade bitumen will vary in detail depending on the form of rubber to be used [7]. In general, the finer the particle size is, the more rapid the blending is. For binders harder than 300 pen., the binder should be heated to a temperature of $140-170^{\circ} \mathrm{C}$ depending on bitumen hardness, in a boiler the capacity of which will allow for at least a $50 \%$ increase in binder volume. The boiler should be fitted with a propeller-type stirrer or other means of agitation which will ensure that any material added to the binder will be drawn down into it. Latex should be added slowly in small quantities and allowed to remain on the surface for about 20 seconds before stirring it. The intensity of foaming should be gauged and the remainder of the latex added at such a rate to ensure that this is not too great for the capacity of the boilier used. After the addition of the latex, the binder should be allowed to cool below $130^{\circ} \mathrm{C}$ unless it is to be used immediately. Stirring should be continued for a minimum of 20 minutes after the addition of the rubber.

The procedure used to obtain the optimum binder contents was in accordance with the Marshall procedure. The binder contents investigated varied from $5.0 \%$ to $7.0 \%$ of total mixture weight, in increments of $0.5 \%$. Three specimens were prepared for each binder content. For mixing purposes, the binder was heated to the temperature that produced a kinematics viscosity of $170 \pm 20$ centistokes, for compaction the required viscosity was $280 \pm 30$ centistokes.

Compaction was carried out by applying 75 blows to each face of the specimens, in accordance with the criterion for heavy traffic. The specimens were weighed in air and in water to determine the bulk specific gravity of the compacted mixes. At each binder content the following mix properties were determined; the specific gravity of the compacted mix, the void in the mineral aggregate (VMA), the voids in the mix (VIM) and the voids filled with the binder (VFB). 


\subsection{Testing of the specimens}

Six Marshall specimens with optimum binder content were prepared for each binder type investigated. Four levels of latex content were investigated in this study, at $0 \%, 2 \%, 4 \%$ and $6 \%$ latex by weight of mix respectively. A wet process was used in the blending of mixtures. Three specimens from each group were tested under the Marshall standard to obtain Marshall stabilty data. The remaining specimens were tested following immersions in a bath at $60^{\circ} \mathrm{C}$ for 24 hours. The percentage that retained Marshall stability provided an indication of the effects of water on the mixes. A higher value indicated higher water resistance.

The retained Marshall stability was used to evaluate resistance to water as some researchers have used retained Marshall stability for evaluating resistance of asphalt mixtures to moisture $[1,8,9,10]$. It is well known that presence of water in a bituminous mix is a critical factor which can lead to premature failure of flexible pavements.

\section{Results and discussion}

The mix made without latex $(0 \%)$ had an optimum binder content of $6.5 \%$. The results of the Marshall tests are summarized in Table 1.

Table 1. Summary of the Design Results of the Marshall Method Compared to Indonesian Specifications

\begin{tabular}{|l|c|c|c|c|}
\hline \multirow{2}{*}{$\begin{array}{c}\text { Design } \\
\text { Parameters }\end{array}$} & \multirow{2}{*}{ Unit } & \multirow{2}{*}{ Value } & \multicolumn{2}{c|}{ Indonesian Specifications } \\
\cline { 4 - 5 } & & & Min & Max \\
\hline Marshall Stability & $\mathrm{kg}$ & 1121 & 800 & - \\
\hline Flow & $\mathrm{mm}$ & 3.39 & 3 & - \\
\hline VIM & $\%$ & 4.74 & 3.5 & 5.5 \\
\hline VMA & $\%$ & 17.74 & 15 & - \\
\hline VFB & $\%$ & 75.66 & 65 & - \\
\hline Marshall Quotient & $\mathrm{kg} / \mathrm{mm}$ & 330 & 250 & - \\
\hline
\end{tabular}

The average Marshall stability and flow value was determined for each binder content. The parameters obtained were then plotted against binder content, namely; stability, flow, unit weight, VIM, VFB and VMA contents for each binder specimen. Optimum Binder Content (OBC) was determined from their graphs and showed in Figure 2.

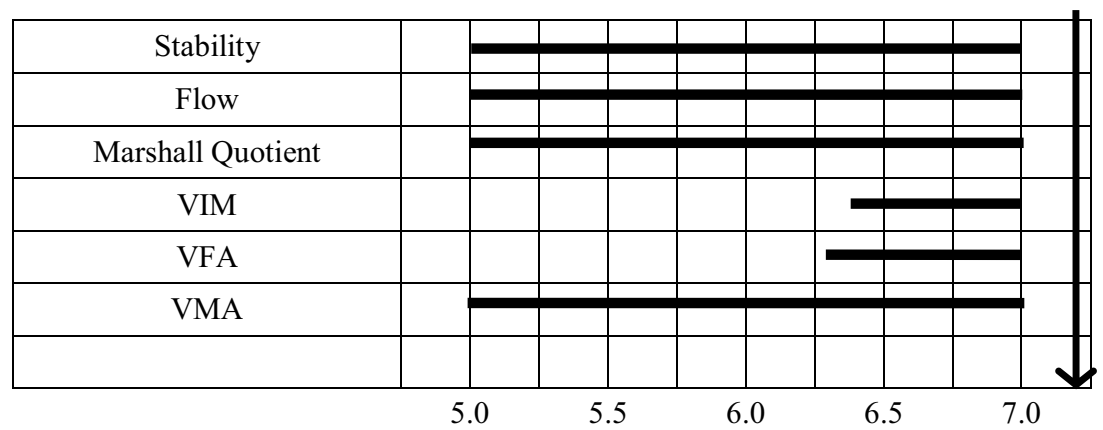

Fig. 2. Determination of Optimum Bitumen Content

All mixtures prepared had this optimum bitumen content. Fig. 3 shows an increase in latex increased stability from $0 \%$ to $4 \%$ which decreased when latex increased to $6 \%$. The mix with $4 \%$ latex had a stability level $13 \%$ higher than that of the mix with no latex $(0 \%)$. 
Adding latex to asphalt affects its softening, penetration index and bitumen film point increase so that the stability of the mix incresases. Stability of the mix is influenced by its components, namely agregate and asphalt binder.

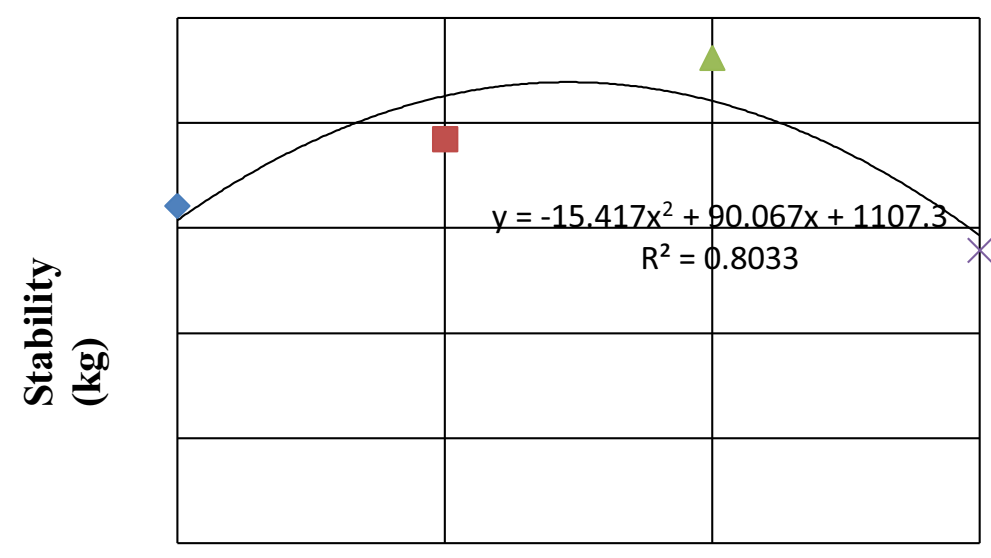

Latex Content

Fig. 3. Variations in the Marshall stabilities of ACWC against Latex Content by Marshall standard tests.

The Marshall immersion tests, Fig. 4, found that stability increased with the rise in latex levels from $0 \%-4 \%$, but decreased when the latex content was increased. Further the mix with $4 \%$ latex had the best stability. Adding $4 \%$ latex made the bitumen film more stable and the more durable. That mixtures with latex contents of over $4 \%$ lost stability was possibly due to the fact this latex excessive and did not blend well.

Fig. 3 and Fig. 4 show that values of Marshall stability under immersion conditions were lower than those of the standard condition for each level of latex content. This was due to the effect of water on Marshall stability values. The absorbed water may have penetrated between the binder film and the aggregate surface causing a weakening in the bonding and adhesion between the aggregate particles, so that immersion of the mixtures decreased the Marshall stability.

Cohesion is developed in a mastic and is influenced by the rheology of the filled binder. The cohesive strength of a mastic is a function of the interaction between the asphalt cement and mineral filler, not just of the individual components alone. The cohesive strength of a mastic is weakened due to the presence of water through increased saturation and void swelling or expansion [11]. 


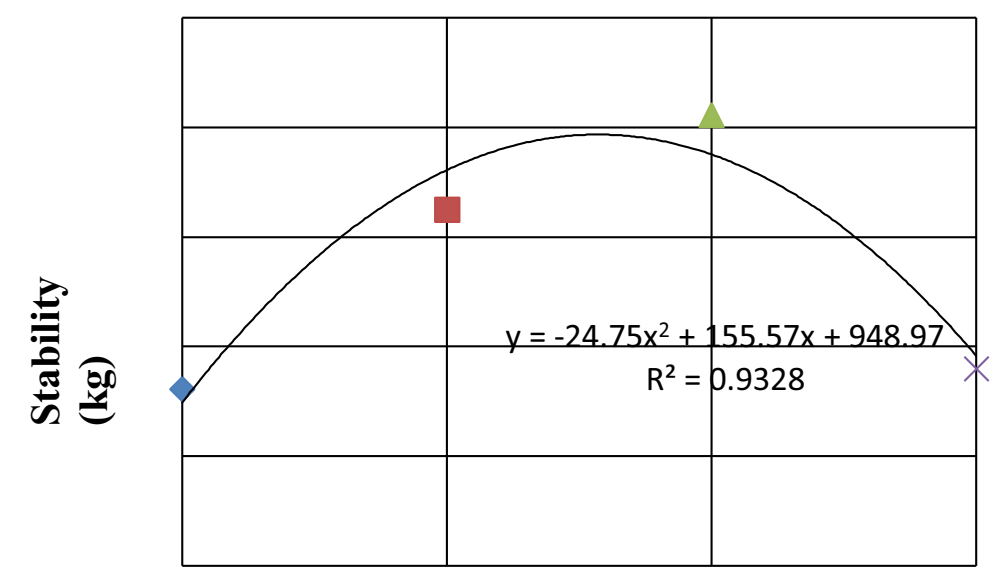

Latex Content

Fig. 4. Variations in the Marshall stabilities of ACWC between differing Latex Contents from Marshall immersion tests.

Fig. 5. Shows that retained stability increased with the increase in latex content from $0 \%$ to $4 \%$ but decreased with higer latex content. The addition of $2 \%$ or $4 \%$ latex appears to improve mix resistance to water significanltly as indicated by the retained stability. A smaller improvement is apparent when $6 \%$ latex is added.The mix with $4 \%$ latex had the highest retained stability value. This is attributed to the fact that the addition of $4 \%$ latex increased the resistance of the ACWC mix to water. In addition, the stability of the mix with no latex $(0 \%)$ differed by $12 \%$ from that with $4 \%$. However, there may be practical problems in producing a uniform blend at this low latex content which corerresponds to a dry rubber content of $2.4 \%$.

Some studies on adding latex to asphalt mixes also showed that it improve the binder and the mixtures performance. The binder test results showed that all the asphat rubber (AR) binders had improved viscosity-temperature susceptibility [12]. By using asphalt rubber as a binder, the film thickness is increased to a value of 19-36 $\mathrm{lm}$ compared to the typical densegraded Hot Mix Asphalt (HMA) film thickness of about $9 \operatorname{lm}$ [13]. 


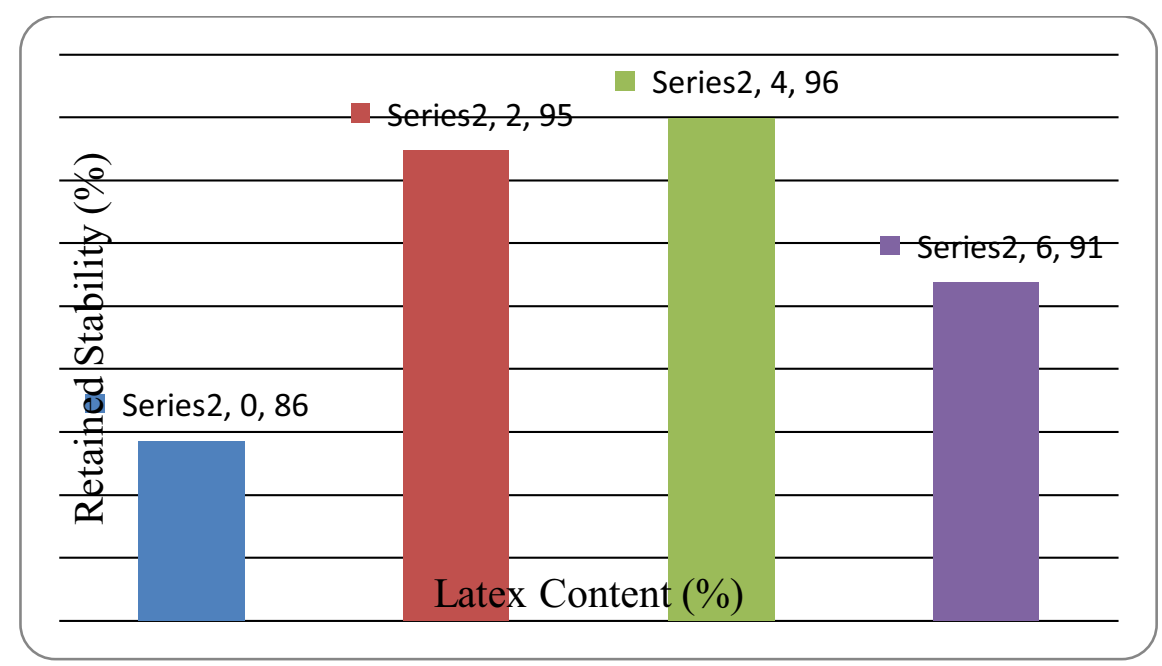

Fig. 5. Variations in ACWC retained Marshall stabilities with differing Latex Contents.

\section{Conclusion}

The results of this study lead to the following conclusions: That the Marshall immersion test results indicated that the addition of up to $4 \%$ latex to ACWC mix increases the retained Marshall stability, that the addition of latex above $4 \%$ decreased the retained stability of the mixture and that the addition of $4 \%$ latex significantly improved mix resistance to water and was the best latex - ACWC mix.

\section{References}

1 K.D. Stuart, A state of art report. (Research Development and Technology, Turner-Fairbank Highway Research Center, 1990)

2 P. Rantetoding, National Symposium Highway Surfacing (1986)

3 C. Gorkem, B. Sengoz: Constr. Build Mater., 23, 2227 (2009)

4 R. Roque, B. Birgisson, C. Drakos, G. Sholar, Guidelines for use of modified binders. (Florida Department of Transportation, Florida, 2005)

5 H. Siswanto, The Research and Studies II Technological and Professional Skill Development Sector Project (Bandung, 2006)

6 N. Vichitcholchai, J. Panmai, N. Na-Ranong, Rubberthai Journal, 1, 39 (2012)

7 Transport Road Research Laboratory, Road Note 36 Specification for the Manufacture and Use of Rubberised Bituminous road materials and binders (HMSO, 1968)

8 A.E.A. Behiry, Ain Shams Eng. J., 4, 353 (2013)

9 A. Hadidy, A. T. Hameed, TJES, 18, 70 (2011)

10 A. Mishhadani, H.A. Baidhani, H.H. Zghair, TJES, 21, 14 (2014)

11 Iowa State University, Evaluation of hot mix asphalt moisture sensitivity using the Nottingham asphalt test equipment, (IHRB Project TR-555, final report, 2010).

12 K.E. Kaloush, Constr. Build. Mater., 67, 260 (2014)

13 Way G, Sousa J. Kaloush K, International RILEM symposium on performance testing and evaluation of bituminous materials, PTEBM'03, 543 (2003) 